(C) 2019 IEEE. Personal use of this material is permitted. Permission from IEEE must be obtained for all other uses, in any current or future media, including reprinting/republishing this material for advertising or promotional purposes, creating new collective works, for resale or redistribution to servers or lists, or reuse of any copyrighted component of this work in other works.

Digital Object Identifier: https://doi.org/10.1109/JPHOTOV.2019.2933357 


\title{
Decoupling of Optical and Electrical Properties of rear contact CIGS Solar Cells
}

\author{
J. M. V. Cunha ${ }^{1,2,3}$, T. S. Lopes ${ }^{1}$, S. Bose ${ }^{1,4}$, A. Hultqvist ${ }^{4}$, W. C. Chen ${ }^{4}$, O. Donzel-Gargand ${ }^{1,4}$, R. M. \\ Ribeiro $^{1}$, A. J. N. Oliveira ${ }^{1}$, M. Edoff ${ }^{4}$, P. A. Fernandes ${ }^{1,3,5}$, P. M. P. Salomé ${ }^{1,2,{ }^{*}}$ \\ ${ }^{1}$ INL - International Iberian Nanotechnology Laboratory, Avenida Mestre José Veiga, 4715-330 Braga, Portugal \\ ${ }^{2}$ Departamento de Física, Universidade de Aveiro, Campus Universitário de Santiago, 3810-193 Aveiro, Portugal \\ ${ }^{3}$ I3N, Universidade de Aveiro, Campus Universitário de Santiago, 3810-193 Aveiro, Portugal \\ ${ }^{4}$ Ångström Laboratory, Solid State Electronics, Ångström Solar Center, Uppsala University, SE-751 21 Uppsala, Sweden \\ ${ }^{5}$ CIETI, Departamento de Física, Instituto Superior de Engenharia do Porto, Instituto Politécnico do Porto, 4200-072, Portugal \\ *corresponding author: P.M.P. Salomé - pedro.salome@inl.int
}

\begin{abstract}
A novel architecture that comprises rear interface passivation and increased rear optical reflection is presented with the following advantages: i) an enhanced optical reflection is achieved by depositing a metallic layer over the Mo rear contact; ii) the addition of a sputtered $\mathrm{Al}_{2} \mathrm{O}_{3}$ layer improves the interface quality with CIGS; and, iii) the rear-openings are refilled with Mo to maintain the optimal ohmic electrical contact as generally observed from the growth of CIGS on Mo. Hence, a decoupling between the electrical function and the optical function of the substrate is achieved. We present in detail the manufacturing procedure of such type of architectures together with its benefits and caveats. A preliminary electrical analysis of resulting solar cells showing a proof-of-concept of the architecture is presented and discussed.
\end{abstract}

\section{INTRODUCTION}

Absorber layers of $\mathrm{Cu}(\mathrm{In}, \mathrm{Ga}) \mathrm{Se}_{2}$ (CIGS) with submicrometer thicknesses, or ultrathin absorbers, are decidedly motivated thin film solar cells research topics. In addition to a lower bill of materials due to its usage reduction, the bulk recombination rate within the CIGS absorber layer may also decrease [1]-[3]. With these two potential benefits, research has been focused on solving the two principal problems that the use of ultrathin devices entail: i) augmented rear interface recombination at the Mo/CIGS interface, and ii) abridged photo-generation due to the width for full absorption being effectively larger than the absorber thickness. In other words, the light-path is significantly thinner than the absorption length. With regards to the rear interface recombination, such effect may also be present in thick films. However, rear interface recombination losses are more pronounced in ultrathin devices. Such losses are higher in ultrathin devices as a larger share of the minority charge carriers are generated closer to the rear contact as compared with standard thick CIGS devices. A solution to mitigate this problem has appeared in the form of a point contact structure made into a dielectric passivation layer with several studies having demonstrated positive effects [1], [4]-[7]. The main limitation of this approach is that the point contacts need to occupy as small area as possible while at the same time being located within distances close enough to avoid resistive losses [8]. This compromise means that the gap between two contacts needs to be of about $1-4 \mu \mathrm{m}$ and in order to decrease the contact area, the opening diameters should be limited from 100 to $400 \mathrm{~nm}$. Hence, recent works have been dealing with the determination of the most suitable dielectric material to be used among $\mathrm{Al}_{2} \mathrm{O}_{3}, \mathrm{SiO}_{2}, \mathrm{Si}_{3} \mathrm{~N}_{4}, \mathrm{Hf}_{2} \mathrm{O}$, etc [1], [5], [6], [9] and what the best patterning approach is [4], [6], [10]-[12]. Until now, e-beam lithography of atomic layer deposited $\mathrm{Al}_{2} \mathrm{O}_{3}$ has been the benchmark of the performed studies [4] and optical lithography of line contacts has shown positive results with the improved benefit of being more industrial-friendly [8]. With regards to optical losses, several approaches have been tested with different outcomes. Z. J. Li-Kao et al. [13], developed an ingenious but complex CIGS lift-off process that moves the CIGS into an $\mathrm{Au}$ substrate allowing for an ohmic contact with excellent reflective properties [14], [15], but unfortunately, the procedure seems to be very complex to be transferred to industry. The replacement of Mo by other metals with higher reflection is yet to be achieved mostly due to metal out-diffusion to the CIGS, selenization of the metal, or poor electrical contact [16], [17]. Moreover, part of the difficulty with increasing rear reflection is related to the coupling of the optical property of this layer with the electrical contacts. Empirically, Mo is known to be the unique solution [18] due, among other things, to the suppression of Se diffusion and the formation of a very thin $\mathrm{MoSe}_{2}$ layer enhancing a good ohmic contact [19]. Hence, an ideal rear contact for ultrathin CIGS layers would need to have: i) Mo as the electrical contact; ii) high optical reflection of the rear contact; and iii) an additional passivation strategy. For these objectives to be met, a decoupling of the optical properties with the electrical properties of the rear contact is required. Hence, in this work we present a process that merges the point contact structure with a metal reflective layer by having Mo in the point contacts. This approach has the benefit that the contacts occupying a short percentage of total interface area are made of Mo, allowing for a good ohmic contact. The rest of the area is left with the passivation material and underneath a highly reflective material that further reduces the optical losses of ultrathin devices. Furthermore, Mo will prevent Se 
diffusion into the metallic interlayers, serving also as a diffusion barrier.

\section{EXPERIMENTAL}

In this section we will present all the preparation of the studied devices with the exception of the new architecture that will be presented in detail in the next section. The usual solar cell stack is: SLG/Mo/CIGS/CdS/i:ZnO/ZnO:Al with $\mathrm{Ni} / \mathrm{Al} / \mathrm{Ni}$ as front contacts [20], with the addition of an evaporated $15 \mathrm{~nm}$ sodium fluoride $(\mathrm{NaF})$ precursor layer on top of the contact structure just prior to the CIGS deposition [21]. The average thickness of CIGS measured using stylus profilometry is $(0.62 \pm 0.05) \mu \mathrm{m}$ with the compositional values of $[\mathrm{Cu}] /([\mathrm{Ga}]+[\mathrm{In}])=0.88 \pm 0.02$ and $[\mathrm{Ga}] /([\mathrm{Ga}]+$ $[\mathrm{In}])=0.31 \pm 0.01$ measured using X-ray fluorescence. Ungraded (flat profile evaporation rates) CIGS absorbers were used for our experiments [4], [22], [23], with a growth temperature of $550{ }^{\circ} \mathrm{C}$. The metal diffusion during CIGS growth can be quite high due to the elevated used temperature. 12 Individual solar cells were defined with an area of $0.5 \mathrm{~cm}^{2}$ as described elsewhere [20]. To study the electrical behavior of the solar cells, illuminated current density versus voltage $(\mathrm{J}-\mathrm{V})$ at AM1.5 and external quantum efficiency (EQE) measurements were performed in home-built systems. Simulations of the solar cells were done using a numerical 3D mesh-based Finite-Difference Time-Domain (FDTD) method to model the optical response of the fabricated structures, employing a specialized commercial solver [4], [17]. A Focused Ion Beam (FIB), Helios NanoLab 450s from FEI, was used to prepare the cross section samples for the Transmission Electron Microscopy (TEM) analysis. The lamella polishing was finished with a low Ga-ion accelerating voltage, below $2 \mathrm{kV}$. The TEM study was performed at 200 $\mathrm{kV}$ on a Titan (G3) Cubed Themis from FEI, utilizing the software Esprit from Bruker.

The samples description and name used hereafter are presented in TABLE I. A reference ultrathin (A) and a reference passivation (B) were fabricated. Moreover, to validate the benefits of the lift-off process, two samples with a Ta interlayer were produced. One sample with a simple Ta interlayer: $\mathrm{Mo} / \mathrm{Ta} / \mathrm{Al}_{2} \mathrm{O}_{3}$ (sample $\mathrm{C}$ ). A second sample with the lift-off process, where $\mathrm{Ta}$ is the interlayer and in addition there is Mo inside the line contacts (sample D) is also studied, as depicted in Figure 1.

TABLE I

SAMPLES DESCRIPTION AND RESPECTIVE NAMING

\begin{tabular}{|c|c|}
\hline Substrate & Description \\
\hline SLG/Mo & (A) Mo reference \\
\hline $\mathrm{SLG} / \mathrm{Mo} / \mathrm{ns}^{-\mathrm{Al}_{2} \mathrm{O}_{3}}$ & (B) Passivation reference \\
\hline $\mathrm{SLG} / \mathrm{Mo} / \mathrm{Ta} / \mathrm{ns}-\mathrm{Al}_{2} \mathrm{O}_{3}$ & (C) Ta interlayer \\
\hline $\begin{array}{c}\mathrm{SLG} / \mathrm{Mo} / \mathrm{Ta} / \mathrm{ns}- \\
\mathrm{Al}_{2} \mathrm{O}_{3} / \mathrm{Mo}\end{array}$ & $\begin{array}{l}\text { (D) Lift-off process with Mo filling the } \\
\text { contacts }\end{array}$ \\
\hline
\end{tabular}

\section{Proposed Architecture AND Processing StePS}

The novel architecture is schematically shown in Figure 1. For a proof-of-concept, we use line contacts instead of point contacts as the point process is more complex and the line contacts are industrially scalable using conventional optical lithography. The dimensions of the lines and their spacing can lead easily to contact resistance losses (seen in $\mathrm{V}_{\mathrm{oc}}$ and $\mathrm{FF}$ losses) so their definition has to be made with care [8]. Hence, $700 \mathrm{~nm}$ lines spaced by a $2.8 \mu \mathrm{m}$ pitch are used in this work as they are known to reduce the rear-interface recombination velocity [8]. In this work we will use Ta as the interlayer for several reasons: i) theoretically, as shown in section IV.B, it has the potential to reflect more light than the standard structure; ii) if not encapsulated fully, it will degrade heavily the CIGS performance trough elemental in- and out-diffusion [7]; and iii) we can etch vertical structures inside Ta using the same ICP etch procedure used for the opening of the $\mathrm{Al}_{2} \mathrm{O}_{3}$ structures.

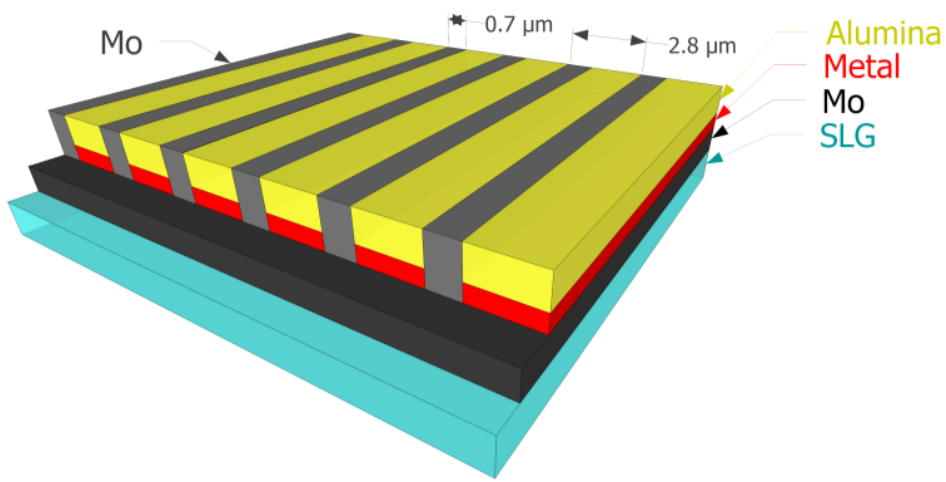

Figure 1: Schematic representation of the developed architecture with Mo filling the line contacts.

The photolithography steps necessary for the substrate fabrication are depicted in Figure 2 and commented in TABLE II. The lithographic definition is done using optical lithography and the $\mathrm{Al}_{2} \mathrm{O}_{3}$ is open with a reactive ion etch step. Ideally, the etching opens both the $\mathrm{Al}_{2} \mathrm{O}_{3}$ and the metal layer. At this point, the photoresist is kept and Mo is deposited. The lift-off allows for Mo to be kept literally inside the line contacts leaving $\mathrm{Al}_{2} \mathrm{O}_{3}$ exposed.

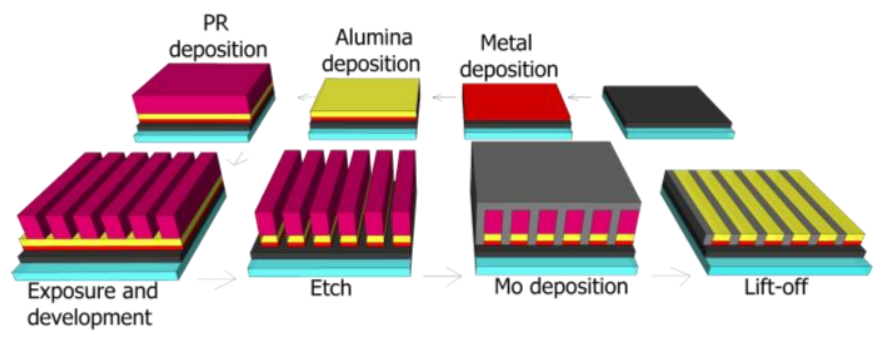

Figure 2: Schematic representation of the photolithography process used for the formation of the line contacts and the deposition of Mo inside. PR is an acronym for Photoresist. 
TABLE II

DETAILED DESCRIPTION OF THE CLEAN ROOM PROCESSING OF THE LIFT-OFF PROCESS THAT PROVIDES FOR A LINE CONTACT STRUCTURE FILLED WITH MO

\begin{tabular}{|c|c|c|}
\hline Step & Description & Properties \\
\hline 0 & SLG substrate & $\begin{array}{c}\text { Cleaning by ultrasounds and } \\
\text { detergent in } \mathrm{H}_{2} \mathrm{O}\end{array}$ \\
\hline 1 & Mo rear contact deposition & $\begin{array}{l}\text { Bilayer Mo, DC-sputtering - } \\
350 \mathrm{~nm} \text { total thickness }\end{array}$ \\
\hline 2 & Metallic layer deposition & DC Sputtering - $10 \mathrm{~nm}$ \\
\hline 3 & Passivation layer deposition & RF sputtering - $18 \mathrm{~nm}$ \\
\hline 4 & $\begin{array}{c}\text { Contact lines creation by DWL } \\
\text { exposure }\end{array}$ & $\begin{array}{c}\text { • HMDS } \\
\text { (hexamethyldisilazane) vapor } \\
\text { priming } \\
\text { - Deposition of photoresist by } \\
\text { spin coating } \\
\text { • Laser exposure } \\
\text { - Pattern development }\end{array}$ \\
\hline 5 & Opening of the contact lines & $\begin{array}{c}\text { Dry etching using reactive ion } \\
\text { etching }\end{array}$ \\
\hline 6 & Mo deposition in the lines & DC-Sputtering - $30 \mathrm{~nm}$ \\
\hline 7 & Lift-off & Ultrasound in an acetone bath \\
\hline 8 & Surface cleaning & $\mathrm{O}_{2}$ Plasma treatment \\
\hline 9 & Solar cell fabrication & $\begin{array}{c}\text { Angstrom Solar cell Baseline } \\
{[20]}\end{array}$ \\
\hline
\end{tabular}

\section{RESULTS}

\section{A. Morphological analysis}

To demonstrate that the lift-off process used in sample D prevents Se diffusion and that the line contacts are clean of $\mathrm{Al}_{2} \mathrm{O}_{3}$ and of Ta, we performed a TEM cross-section EDS analysis. Figure 3 shows the EDS maps for Mo, Al, Ta, Se and $\mathrm{Cu}$. The EDS analysis was performed at the border between a line contact and the $\mathrm{Ta} / \mathrm{Al}_{2} \mathrm{O}_{3}$ insulated area. The analysis shows: i) there is no Se diffusion into the $\mathrm{Al}_{2} \mathrm{O}_{3}$, or inside the line contact, demonstrating that the second Mo layer prevents Se diffusion; ii) the lift-off Mo layer inside the line contact superimposes the line edge, further preventing lateral diffusion; and iii) the etching process fully removes $\mathrm{Al}$ from the line contact allowing for electrical contact. This analysis, in particular, leaves the hypothesis that some Ta is still inside the line contact. While such small layer is very thin and trapped in-between Mo, we decided to also perform an EDS line scan inside the middle line contact. The EDS line scan measurements are shown in Figure 4 and Figure 5, for outside the line and inside the line, respectively. Both EDS line scans show very well-defined structures which withstood the harsh CIGS co-evaporation process. Furthermore, Figure 8 shows no presence of Ta in the line contact, evidencing that in the line contact, we have the expected $\mathrm{Mo} / \mathrm{Mo} / \mathrm{CIGS}$ structure. Thus, a successful etching of Ta and $\mathrm{Al}_{2} \mathrm{O}_{3}$ and a successful second Mo deposition has been obtained. We note that both analyses, and also the EDS mapping, show a residual amount of Mo in the CIGS, but this is only a background signal emanating from the Mo TEM grid used for the study.

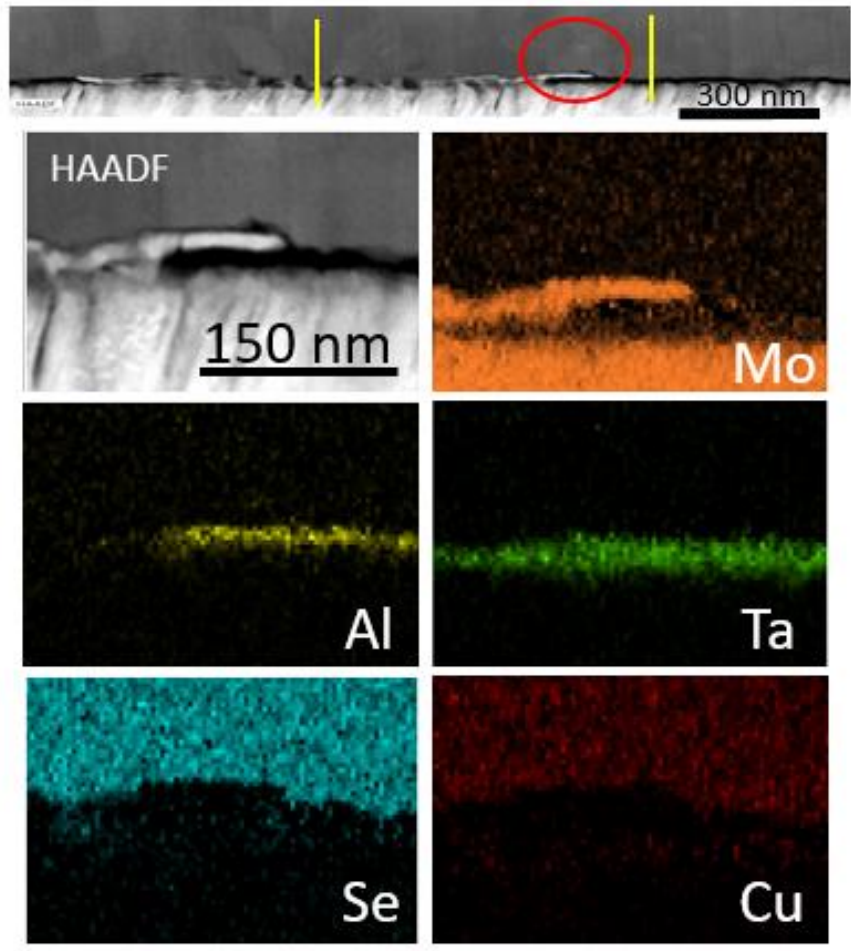

Figure 3: TEM HAADF cross-section image and EDS mapping of sample D. The red circle corresponds to the EDS mapping area while the vertical yellow lines correspond to the line scan regions.

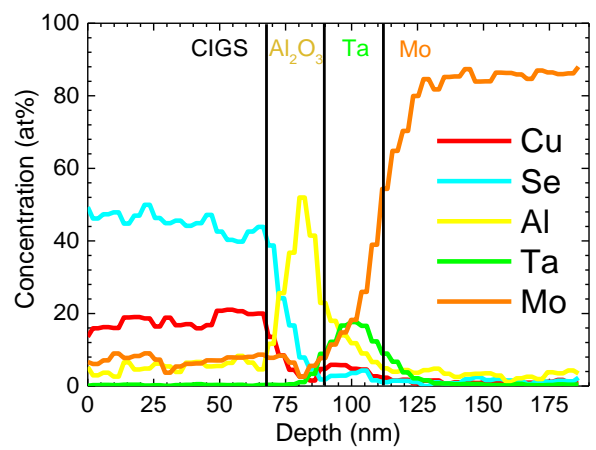

Figure 4: EDS line scan passivated $\mathrm{Mo} / \mathrm{Ta} / \mathrm{Al}_{2} \mathrm{O}_{3} / \mathrm{CIGS}$. The vertical lines are guides to the eye showing the layered passivation structure.

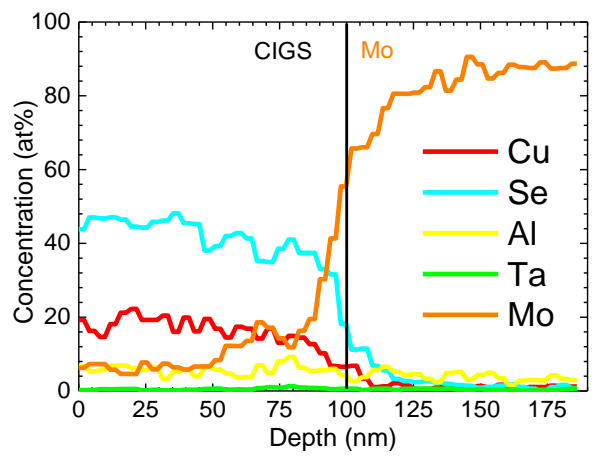

Figure 5: EDS line scan Mo/CIGS inside line contact. The vertical lines are guides to the eye showing the well-defined Mo/CIGS line contact. 


\section{B. Electrical Characterization}

The J-V measurements, depicted in Figure 6 and its respective figures of merit are shown in TABLE III. The J-V results as well as the EQE results (Figure 7) confirm the benefits of employing rear passivation by comparing a Mo reference (sample A) with a passivation reference (sample B), as expected and widely proven so far [1], [4], [6], [10], [17], [24]-[26]. The reference sample (A) shows a low average efficiency (5.4\%), which although it is a low value, it is within the range of values presented in the literature. Ultrathin CIGS devices need optimizations different than the ones of regular thickness CIGS and this fact causes runs to be more variable than their thick counterparts. Sample A also shows evidence of voltage-dependent current collection (VDCC) and/or shunting, which is typical of ultrathin CIGS solar cells. Such problems are explained in more detail elsewhere [4]. As such, the reference sample (A) has a low fill factor (FF), which is recovered by the passivation reference (B), with shunts mitigation by the passivation layer. We observe that sample $\mathrm{D}$ features the highest values of $\mathrm{V}_{\mathrm{oc}}$, FF and efficiency, reaching an average light to power conversion efficiency of $9.6 \%$. Such value is $4.2 \%$ (abs) higher than the reference sample and $2.4 \%$ (abs) higher than the passivated sample. Sample D $\mathrm{V}_{\text {oc }}$ value is $24 \mathrm{mV}$ higher than the passivated sample, hence, the passivation effect is still present and reinforced. Furthermore, there seems to be a $\mathrm{J}_{\mathrm{sc}}$ improvement of 0.25 $\mathrm{mA} / \mathrm{cm}^{2}$, which may be related with an increased reflection of the tantalum material and that will be discussed further in the text. To demonstrate the importance of the Mo second layer deposited in the line contacts, we also produced sample C which allows Se to be in direct contact with Ta. Sample C shows poor solar cell results, most likely due to diffusion of elements and/or a poor electrical contact between $\mathrm{Ta}$ and CIGS showing the importance of process D. This comparison highlights the importance of a diffusion barrier, also in accordance with previous results [16], [17]. The champion cell of process D achieved an efficiency value of $10.0 \%$. Moreover, sample D shows an excellent diode-like behavior, with the lowest dark current $\left(\mathrm{J}_{0}\right)$ value $\left(\sim 4 \times 10^{-6} \mathrm{~mA} / \mathrm{cm}^{2}\right)$, no evidence of either shunting, seen by the high shunt resistance value, or roll-over effects which is demonstrated by its high FF value $(\sim 70 \%)$.

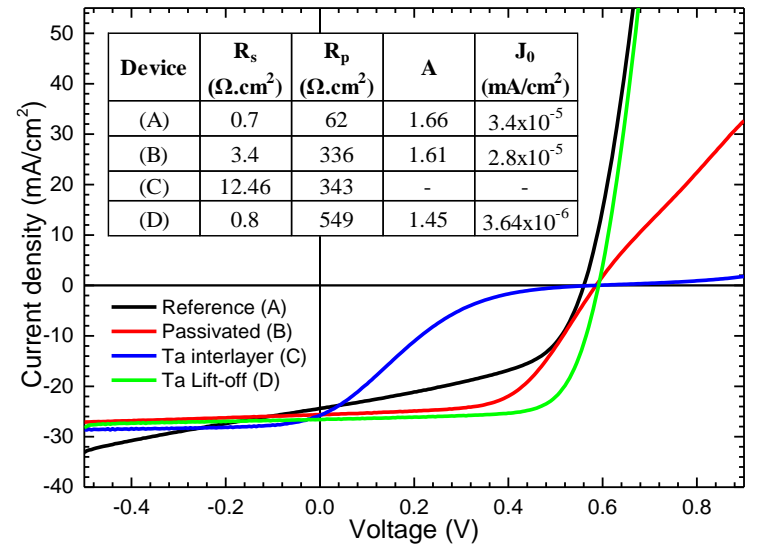

Figure 6: Illuminated $\mathrm{J}-\mathrm{V}$ curves of the highest $\mathrm{V}_{\mathrm{oc}}$ device for all samples. The diode parameters are found on the inset table.

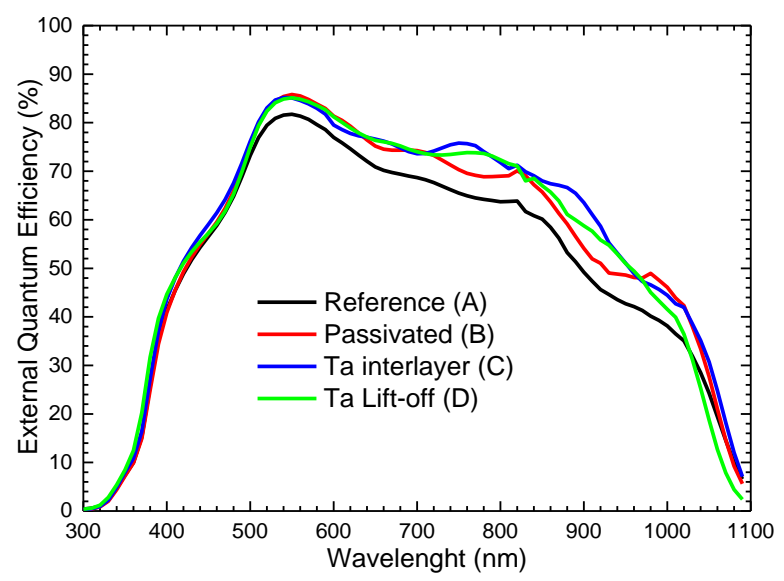

Figure 7: External Quantum Efficiency of the studied samples.

TABLE III

J-V VALUES AVERAGES AND STANDARD DEVIATION OF 12 DEVICES FOR EACH SUBSTRATE TYPE. IN PARENTHESIS THE VALUES FOR THE HIGHEST VOC DEVICE.

\begin{tabular}{|c|c|c|c|c|}
\hline Sample & $\mathbf{V}_{\mathbf{~ o c}}(\mathbf{m V})$ & $\begin{array}{c}\mathbf{E Q E} \\
\mathbf{c o r r e c t e d} \\
\mathbf{J}_{\mathbf{s c}}\left(\mathbf{m A} / \mathbf{c m}^{2}\right)\end{array}$ & $\mathbf{F F}(\%)$ & Eff (\%) \\
\hline (A) & $535 \pm 11$ & $\begin{array}{c}21.37 \pm 0.32 \\
(21.82)\end{array}$ & $\begin{array}{c}47.5 \pm 4.6 \\
(49.9)\end{array}$ & $\begin{array}{c}5.4 \pm 0.7 \\
(6.4)\end{array}$ \\
\hline (B) & $558 \pm 23$ & $23.13 \pm 0.18$ & $55.2 \pm 2.5$ & $7.2 \pm 0.7$ \\
$(560)$ & $(586)$ & $(23.46)$ & $(58.5)$ & $(8.2)$ \\
\hline (C) & $519 \pm 41$ & $24.35 \pm 0.71$ & $14.5 \pm 2.0$ & $1.8 \pm 0.2$ \\
$(579)$ & $(24.96)$ & $(15.7)$ & $(2.2)$ \\
\hline & $582 \pm 5$ & $23.38 \pm 0.29$ & $68.0 \pm 3.4$ & $9.6 \pm 0.5$ \\
(D) & $(591)$ & $(23.59)$ & $(71.7)$ & $(10.0)$ \\
\hline
\end{tabular}

\section{Optical Simulations}

To better understand the optical gains of using Ta underneath the passivation layer, we will proceed to an optical simulation of the novel stack of Figure 1, and compare it with the EQE 
results of Figure 7 for the most important samples identified previously (A, B and D). It is noted that the optical simulations performed do not account for electrical losses, light scattering in grain boundaries, doping and compositional CIGS variations, interface smearing, just to name a few parameters that influence real devices. Therefore, a difference is expected between the simulated values and the measured ones. Nonetheless, the optical simulations (Figure 8) are in good agreement with the $\mathrm{EQE}$ even confirming that by adding the passivation layer, an optical effects leads to an increase of $\mathrm{J}_{\mathrm{sc}}$ values. However, the experimental $\mathrm{J}_{\mathrm{sc}}$ difference between $\mathrm{A}$ and $\mathrm{B}\left(1.76 \mathrm{~mA} / \mathrm{cm}^{2}\right)$ is higher than the simulated $\mathrm{J}_{\mathrm{sc}}$ difference $\left(0.5 \mathrm{~mA} / \mathrm{cm}^{2}\right)$. Such inconsistency is an evidence that part of the $\mathrm{J}_{\mathrm{sc}}$ increase in sample $\mathrm{B}$ is due to electrical passivation and that further passivation optimization is needed. This fact is also highlighted by the observation that in the absorption calculations there is no difference between the samples behavior in the short wavelength regime, contrary to what is observed in the EQE results, where the samples with passivation present a higher behavior even where no optical gains are expected. Such increase in the EQE behavior in all wavelength values when passivation is added is observed throughout the literature and needs to be studied in detail. We also note that the experimental $\mathbf{J}_{\mathrm{sc}}$ difference between $\mathrm{B}$ and $\mathrm{D}$ $\left(0.25 \mathrm{~mA} / \mathrm{cm}^{2}\right)$ is very close to the simulated $\mathrm{J}_{\mathrm{sc}}$ value $(0.2$ $\mathrm{mA} / \mathrm{cm}^{2}$ ), an indication that the passivation is the same in both substrates and that the simulation is reasonably in agreement with the experimental results. Furthermore, by using the novel architecture of sample $\mathrm{D}$, a decrease of parasitic absorption at the rear contact is reached, as shown in the dashed lines of Figure 8. According to the simulations and with regards to parasitic absorption in the rear contact, sample $\mathrm{A}$ has a $\mathbf{J}_{\mathrm{sc}}$ loss of $1.53 \mathrm{~mA} / \mathrm{cm}^{2}$ in the Mo layer, sample B of $1.03 \mathrm{~mA} / \mathrm{cm}^{2}$ in the $\mathrm{Mo}+\mathrm{Al}_{2} \mathrm{O}_{3}$ layer and remarkably, sample $\mathrm{D}$ of 0.86 $\mathrm{mA} / \mathrm{cm}^{2}$ in the $\mathrm{Mo}+\mathrm{Ta}+\mathrm{Al}_{2} \mathrm{O}_{3}+$ Mo. Such solution of decreasing parasitic absorption at the rear contact is highly interesting even for standard thickness CIGS $(2000 \mathrm{~nm})$ where the Mo absorptance can also reach values higher than 1 $\mathrm{mA} / \mathrm{cm}^{2}$ [27]. We note that for even higher reflectivity metals, other losses that are already present here, start to be even more prominent, namely reflection losses, bringing the need to incorporate more advance light trapping mechanisms. Nonetheless, even with the improved novel architecture, the $\mathbf{J}_{\mathrm{sc}}$ values are still far away from simulated values, likely meaning that not only light trapping has to be improved but also the interface recombination velocity has to be further reduced.

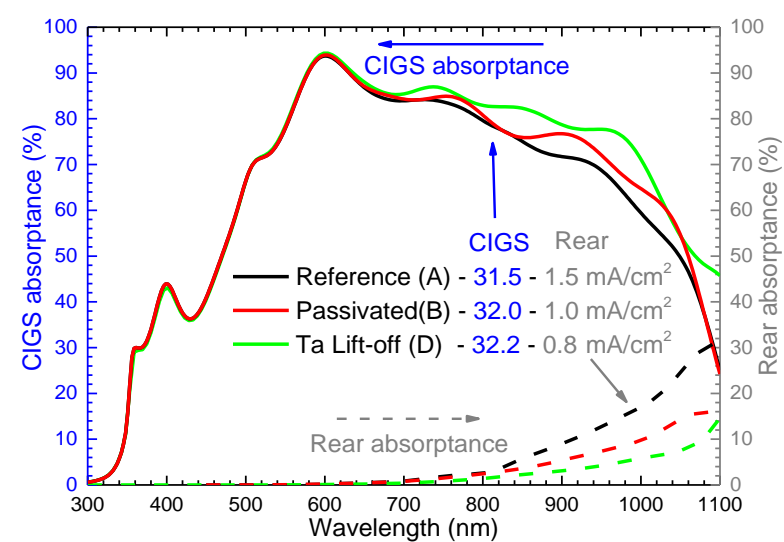

Figure 8: Simulated CIGS absorptance and rear contact absorptance. For sample A, rear contact absorptance is the Mo absorptance, for sample $\mathrm{B}$ it is $\mathrm{Mo}+\mathrm{Al}_{2} \mathrm{O}_{3}$ absorptance and for sample $\mathrm{D}$ it is the absorptance of $\mathrm{Mo}+\mathrm{Ta}+\mathrm{Al}_{2} \mathrm{O}_{3}+\mathrm{Mo}$.

\section{CONCLUSIONS}

In this preliminary work, we introduced a lift-off procedure to fabricate a substrate for thin film solar cells that decouples the electrical properties from the optical properties. This is accomplished by having the electrical contact being made by a Mo line contact that uses only a part of the available area. The rest of the area is passivated by an $\mathrm{Al}_{2} \mathrm{O}_{3}$ layer which underneath can have a highly reflective metal layer. Solar cells with the novel process and $\mathrm{Ta}$ as an interlayer show an improvement over reference devices and a significant improvement over substrates with Ta without the lift-off process. The $600 \mathrm{~nm}$ CIGS thickness solar cells with the new process achieved an average efficiency of $9.6 \%$ which compares with the unpassivated reference with $5.4 \%$.

The new architecture allows for: i) good electrical contact between the CIGS and the rear contact; ii) a positive passivation effect; iii) a reduced rear contact light absorptance; and iv) a limitation to the diffusion from and to the absorber layer. Such architecture allows for a wider ensemble of metals to be used to increase the rear reflectance as most limitations of other metals can now be overcome. Future studies should be focused on studying the effects of this architecture, on improving the lift-off process and on testing highly reflective metals like $\mathrm{Au}, \mathrm{Ag}$ and $\mathrm{Cu}$.

\section{ACKNOWLEDGEMENTS}

Fundação para a Ciência e a Tecnologia (FCT) is acknowledged trough: IF/00133/2015 and PD/BD/142780/2018. The European Union's Horizon 2020 research and innovation programme ARCIGS-M project (grant agreement no. 720887) is acknowledged. This research is also supported by NovaCell (028075) and InovSolarCells (029696) co-funded by FCT and the ERDF through COMPETE2020. We would like to thank Fundação Luso-Americana para o Desenvolvimento (FLAD) for support via project 2019/CON8/CAN19. 


\section{REFERENCES}

[1] B. Vermang, V. Fjällström, J. Pettersson, P. Salomé, and M. Edoff, "Development of rear surface passivated $\mathrm{Cu}(\mathrm{In}, \mathrm{Ga}) \mathrm{Se}_{2}$ thin film solar cells with nano-sized local rear point contacts," Sol. Energy Mater. Sol. Cells, vol. 117, pp. 505-511, Oct. 2013.

[2] J. Krc, M. Sever, A. Campa, Z. Lokar, B. Lipovsek, and M. Topic, "Optical confinement in chalcopyrite based solar cells," Thin Solid Films, vol. 633, pp. 193-201, Jul. 2017.

[3] J. M. V. Cunha, C. Rocha, C. Vinhais, P. A. Fernandes, and P. M. P. Salomé, "Understanding the AC Equivalent Circuit Response of Ultrathin $\mathrm{Cu}(\mathrm{In}, \mathrm{Ga}) \mathrm{Se}_{2}$ Solar Cells," accepted in IEEE J. Photovoltaics, 2019.

[4] P. M. P. Salomé et al., "Passivation of Interfaces in Thin Film Solar Cells: Understanding the Effects of a Nanostructured Rear Point Contact Layer," Adv. Mater. Interfaces, vol. 5, no. 2, p. 1701101, Jan. 2018.

[5] B. Vermang et al., "Employing Si solar cell technology to increase efficiency of ultra-thin $\mathrm{Cu}(\mathrm{In}, \mathrm{Ga}) \mathrm{Se}_{2}$ solar cells," Prog. Photovoltaics Res. Appl., vol. 22, no. 10, pp. 1023-1029, Oct. 2014.

[6] G. Yin et al., "Well-Controlled Dielectric Nanomeshes by Colloidal Nanosphere Lithography for Optoelectronic Enhancement of Ultrathin $\mathrm{Cu}(\mathrm{In}, \mathrm{Ga}) \mathrm{Se}_{2}$ Solar Cells," ACS Appl. Mater. Interfaces, vol. 8, no. 46, pp. 31646-31652, Nov. 2016.

[7] B. Vermang et al., "Rear Surface Optimization of CZTS Solar Cells by Use of a Passivation Layer With Nanosized Point Openings," IEEE J. Photovoltaics, vol. 6, no. 1, pp. 332-336, Jan. 2016.

[8] S. Bose et al., "Optical Lithography Patterning of $\mathrm{SiO}_{2}$ Layers for Interface Passivation of Thin Film Solar Cells," Sol. RRL, vol. 2, no. 12, p. 1800212 , Dec. 2018.

[9] J. M. V. Cunha et al., "Insulator Materials for Interface Passivation of $\mathrm{Cu}(\mathrm{In}, \mathrm{Ga}) \mathrm{Se}_{2}$ Thin Films," IEEE J. Photovoltaics, vol. 8, no. 5, pp. 1313-1319, Sep. 2018.

[10] S. Bose et al., "A morphological and electronic study of ultrathin rear passivated $\mathrm{Cu}(\mathrm{In}, \mathrm{Ga}) \mathrm{Se}_{2}$ solar cells," Thin Solid Films, vol. 671, pp. 77-84, Feb. 2019.

[11] S. Choi, Y. Kamikawa, J. Nishinaga, A. Yamada, H. Shibata, and S. Niki, "Lithographic fabrication of point contact with $\mathrm{Al}_{2} \mathrm{O}_{3}$ rear-surface-passivated and ultra-thin $\mathrm{Cu}(\mathrm{In}, \mathrm{Ga}) \mathrm{Se}_{2}$ solar cells," Thin Solid Films, vol. 665, pp. 91-95, Nov. 2018.

[12] G. Yin, P. Manley, and M. Schmid, "Light trapping in ultrathin $\mathrm{CuIn}_{1-\mathrm{x}} \mathrm{Ga}_{\mathrm{x}} \mathrm{Se}_{2}$ solar cells by dielectric nanoparticles," Sol. Energy, vol. 163, pp. 443-452, Mar. 2018.

[13] Z. J. Li-Kao et al., "Towards ultrathin copper indium gallium diselenide solar cells: proof of concept study by chemical etching and gold back contact engineering," Prog. Photovoltaics Res. Appl., vol. 20, no. 5, pp. 582-587, Aug. 2012.

[14] N. Naghavi et al., "Ultrathin $\mathrm{Cu}(\mathrm{In}, \mathrm{Ga}) \mathrm{Se}_{2}$ based solar cells," Thin Solid Films, vol. 633, pp. 55-60, Jul. 2017.

[15] N. Dahan et al., "Optical approaches to improve the photocurrent generation in $\mathrm{Cu}(\mathrm{In}, \mathrm{Ga}) \mathrm{Se}_{2}$ solar cells with absorber thicknesses down to $0.5 \mu \mathrm{m}$," J. Appl. Phys., vol. 112, no. 9, p. 094902, Nov. 2012.

[16] K. Orgassa, H. W. Schock, and J. H. Werner, "Alternative back contact materials for thin film $\mathrm{Cu}(\mathrm{In}, \mathrm{Ga}) \mathrm{Se}_{2}$ solar cells," Thin Solid Films, vol. 431432, pp. 387-391, May 2003.

[17] T. S. Lopes et al., "Rear Optical Reflection and Passivation Using a Nanopatterned Metal/dielectric Structure in Thin Film Solar Cells," July 2019IEEE Journal of Photovoltaics PP(99):1-7, DOI: 10.1109/JPHOTOV.2019.2922323

[18] P. M. P. Salomé, J. Malaquias, P. A. Fernandes, and A. F. da Cunha, "Mo bilayer for thin film photovoltaics revisited," J. Phys. D. Appl. Phys., vol. 43, no. 34, p. 345501, Sep. 2010.

[19] P. Salomé, V. Fjällström, A. Hultqvist, and M. Edoff, "Na Doping of CIGS Solar Cells Using Low SodiumDoped Mo Layer," IEEE J. Photovoltaics, vol. 3, no. 1, pp. 509-513, Jan. 2013.

[20] J. Lindahl et al., "Inline $\mathrm{Cu}(\mathrm{In}, \mathrm{Ga}) \mathrm{Se}_{2} \mathrm{Co}$-evaporation for High-Efficiency Solar Cells and Modules," IEEE J. Photovoltaics, vol. 3, no. 3, pp. 1100-1105, Jul. 2013.

[21] P. M. P. Salomé et al., "Cu(In,Ga)Se ${ }_{2}$ Solar Cells With Varying Na Content Prepared on Nominally Alkali-Free Glass Substrates," IEEE J. Photovoltaics, vol. 3, no. 2, pp. 852-858, Apr. 2013.

[22] P. M. P. Salomé et al., "The effect of high growth temperature on $\mathrm{Cu}(\mathrm{In}, \mathrm{Ga}) \mathrm{Se}_{2}$ thin film solar cells," Sol. Energy Mater. Sol. Cells, vol. 123, pp. 166-170, Apr. 2014.

[23] O. Lundberg, M. Edoff, and L. Stolt, "The effect of Ga-grading in CIGS thin film solar cells," Thin Solid Films, vol. 480-481, pp. 520-525, Jun. 2005.

[24] B. Vermang et al., "Introduction of Si PERC Rear Contacting Design to Boost Efficiency of $\mathrm{Cu}(\mathrm{In}, \mathrm{Ga}) \mathrm{Se}_{2}$ Solar Cells," IEEE J. Photovoltaics, vol. 4, no. 6, pp. 1644-1649, Nov. 2014.

[25] M. Schmid, "Review on light management by nanostructures in chalcopyrite solar cells," Semicond. Sci. Technol., vol. 32, no. 4, p. 043003, Apr. 2017.

[26] G. Birant, J. de Wild, M. Meuris, J. Poortmans, and B. Vermang, "Dielectric-Based Rear Surface Passivation Approaches for Cu(In,Ga)Se ${ }_{2}$ Solar Cells-A Review," Appl. Sci., vol. 9, no. 4, p. 677, Feb. 2019. 
[27] B. Bissig et al., "Novel back contact reflector for high efficiency and double-graded $\mathrm{Cu}(\mathrm{In}, \mathrm{Ga}) \mathrm{Se}_{2}$ thin-film solar cells," Prog. Photovoltaics Res. Appl., vol. 26, no. 11, pp. 894-900, Nov. 2018. 